\title{
Pricing of Embedded Options in Bank Deposits and Loans Based on Jump-Diffusion Interest Rate Model
}

\author{
Enlin Tang ${ }^{1}$ and Song Xu $\mathbb{D}^{2}$ \\ ${ }^{1}$ School of Finance and Mathematics, Huainan Normal University, Huainan 232038, China \\ ${ }^{2}$ Construction Economics and Real Estate Management Research Center, Anhui Jianzhu University, Hefei 230009, China
}

Correspondence should be addressed to Song Xu; songxuxs@gmail.com

Received 5 March 2021; Revised 12 April 2021; Accepted 20 April 2021; Published 17 May 2021

Academic Editor: Ahmed Mostafa Khalil

Copyright (c) 2021 Enlin Tang and Song Xu. This is an open access article distributed under the Creative Commons Attribution License, which permits unrestricted use, distribution, and reproduction in any medium, provided the original work is properly cited.

\begin{abstract}
The marketization of interest rate is an inevitable requirement for China's financial reform and joining the WTO to connect with the international financial market. It is also an important link to improve the marketization degree of China's financial system. The marketization of interest rate in China is gradually advancing according to its preset mode. In the process of interest rate marketization, an unavoidable problem is that while the interest rate marketization gives the commercial banks the autonomy of capital pricing, the fluctuation of interest rate is more and more frequent. However, due to the fluctuation of interest rate, the loan as the main assets of commercial banks will be prepayed by borrowers, and the time deposit as the main liabilities of commercial banks will be withdrawn by depositors in advance; that is, embedded options are implied in asset liability items, which makes it difficult for commercial banks to accurately calculate the actual interest margin of deposits and loans and manage the interest rate risk. Therefore, it is of great significance to identify and price such embedded option value. On the basis of identifying and decomposing the embedded options in deposit and loan of commercial banks, according to the change characteristics of deposit and loan interest rate of Chinese commercial banks, this paper chooses jump-diffusion interest rate model to describe the change of benchmark interest rate of deposit and loan in China and demonstrates the advantages of this model compared with other models. Based on Monte Carlo simulation technology, the embedded options of five-year fixed deposit and ten-year prepayable loan in China are priced. On this basis, it points out that the real interest margin of commercial bank's deposit and loan should be the nominal interest margin minus the value of deposit and loan's embedded options. In the process of interest rate risk management, we should pay attention to the existence of embedded options and carry out effective management.
\end{abstract}

\section{Introduction}

Embedded options refer to the options embedded in bank assets and liabilities. When the interest rate fluctuates greatly, the customers of the bank will exercise the option implied in the assets or liabilities for the purpose of selfinterest (such as prepaying the loan or withdrawing the time deposit in advance), thus bringing uncertainty to the bank's income [1]. This uncertainty obviously constitutes a source of risk, which is called "embedded option risk." With the advancement of interest rate marketization in China, financial derivatives with interest rate as the subject matter are increasing. At the same time, assets and liabilities with embedded option are increasingly appearing in the balance sheets of banks and other financial institutions [2, 3]. However, in China's current financial products, including time deposits, mortgage loans, and mortgage loans, there is no pricing for the embedded options implied in deposits and loans, which leads to the pricing of deposits and loans too low. With the advancement of interest rate marketization in China, the existence of embedded options has become one of the important reasons for the interest rate risk of banks and other financial institutions. Therefore, it is of great significance for China's commercial banks to study the pricing technology of embedded option implied in the assets and liabilities of banks and other financial institutions in terms of product development and risk management. Through the collection of option fee, banks can reduce their operating 
costs and refinancing risks and increase their liquidity. It is of great theoretical and practical significance to measure and control the prepayment risk of assets and the withdrawal risk of liabilities and to establish a practical and effective asset liability portfolio optimization model, which can provide decision support for the risk control of commercial banks and the optimal allocation of asset structure.

\section{Literature Review}

The sharp fluctuation of interest rate and the sharp increase in interest rate risk in the international financial market have attracted many scholars' in-depth research on the measurement of interest rate risk and the corresponding management and control technology. Foreign scholars' research on embedded options and interest rate risk was started earlier and made outstanding achievements. On the pricing of embedded options, Easton [4] studied the principle and method of pricing embedded options in Asian options by Monte Carlo simulation and obtained the bond price with Asian options through parameter estimation. Gilkson and Ruff [5] studied the early withdrawal problem of small retail CDs and proposed a pricing method of CDs with early withdrawal right. Glikson et al. [6] analyzed the correlation between the interest rate level and the embedded option value in CDs by using cross-sectional data. The research shows that there is a general phenomenon of early withdrawal of long-term time deposits, and the early withdrawal behavior of depositors increases with the increase in interest rate. Brooks [7] calculated the annual percentage yield (APY) and effective annual rate (EAR) of CDs to analyze the actual yield level of products. Tolstykh et al. [8] also found that the risk of embedded options may come from the change of asset and liability convexity, which will lead to unexpected changes in asset and liability prices. Turner et al. [9] studied the embedded options in deposits and analyzed the characteristics of options that are beneficial to depositors in time deposits and the time characteristics of depositors' exercise of options. Cline and Brooks [10] analyzed the characteristics of some exotic CDs in recent years and their pricing [11].

Domestic research on embedded options is more about the risk management of embedded options or the measurement of risk. For example, Wang and Zhang [12] constructed the goal programming model of interest rate risk management and thought that compared with the duration gap model, the convexity gap model had better effect in reducing interest rate risk. Luo and Wan [13] studied the interest rate risk control of bank's assets and liabilities when the embedded option exists and proposed the control strategy of interest rate risk. Zheng and Lin [14] proposed a new standard to measure the impact of embedded options on bond interest rate risk and used the binary tree model to make an empirical analysis on the callable and resolvable financial bonds issued by China Development Bank. Ren and Li [15] selected the Vasicek interest rate model and used the method of partial differential equation to approximate the calculation formula of time deposit value. Yang [16] focused on the effective duration and effective convexity model based on embedded option and option-adjusted spread and studied its specific application in the interest rate risk management of commercial banks in China. Dai [17] used no arbitrage pricing method and OAS method to calculate the embedded options based on the decomposition of the embedded options. Yi and Liu [18] used the Monte Carlo simulation method and trigeminal tree method to reconstruct the interest rate trend, and based on this, they studied the interest rate risk of embedded options. However, there is little research on the pricing of embedded options. Zheng and Lin [19] used no arbitrage analysis method and numerical calculation method to price the embedded options and made the sensitivity analysis of the option price to various factors. Liu et al. [20] established the mathematical model of prepayable loan under the CIR interest rate model and discussed the influence of stochastic interest rate on prepayment. Zhu et al. [21] divided the embedded options of deposits into two parts such as interest rate risk and liquidity risk and used the numerical analysis method to price the fair value of the two parts. Zhu et al. [22] used the trigeminal tree analysis method to price the embedded options. Xia et al., [23] priced the deposit and loan with embedded options, and on this basis, they analyzed the impact of embedded options on the interest rate risk management of commercial banks.

Through literature review, we find that in recent years, although Chinese scholars have gradually begun to study the interest rate risk of financial instruments with embedded options, the above research mainly focuses on the measurement of interest rate risk with embedded options, as well as the analysis of the risk caused by the prepayment of loans or the analysis of the characteristics of embedded options. There is a lack of research on the pricing of embedded options in deposits and loans, especially the advance execution of embedded options in deposits and loans based on the dynamic change of interest rate. As an inducement of interest rate risk, it is an inevitable choice for Chinese banks to price the embedded option scientifically in the face of external shocks after the interest rate liberalization. Generally speaking, the research on interest rate risk of financial institutions in China started relatively late, and the research on pricing model and practical application of interest rate derivatives such as embedded options is rare. This situation needs to be changed in the innovation and development of financial instruments today. In addition, in terms of research methods, the arbitrage free analysis method and differential equation method proposed by predecessors are all based on a series of harsh assumptions, and in more complex cases (such as adding the jump factor of interest rate), they may not be able to get accurate solutions. Based on its own advantages, the Monte Carlo simulation method can solve multidimensional securities pricing, which will become the development trend of this kind of financial product pricing.

\section{Recognition of Embedded Options in Bank Deposits and Loans}

3.1. Decomposition of Embedded Options in Bank Deposits and Loans. In the asset business of banks, loans account for the largest proportion of assets. Loans can be divided into 
floating rate loans and fixed rate loans [24]. For the fixed rate loan, the borrower must pay a fixed amount of interest to the bank according to the fixed interest rate under normal circumstances. Therefore, the fixed rate loan can be regarded as a redeemable bond issued by the borrower to the bank. The face value of the redeemable bond is equal to the face value of the loan, and the execution price is the loan interest rate. For banks, it is equivalent to the buyer of callable bonds, and it is short of American put options; the borrower is equivalent to the issuer of callable bonds and is also the bull of American put options. As shown in Figure 1, this is equivalent to the bank issuing an American put option to the borrower and the borrower issuing a bond to the bank.

When banks make loan pricing, they often only pay attention to the content of (2) in Figure 1 and ignore the content of (1) in Figure 1. In theory, the borrower should pay a certain option fee to the bank when he obtains the American option. Otherwise, banks should consider the existence of options when they determine the interest rate. However, for the consideration of laws and regulations or industry competition, banks ignore the existence of options. When the interest rate drops, the rational borrower will choose to repay in advance, and then apply to the bank for a loan with lower interest rate. The value of options will determine the motivation of borrowers to prepay. When the interest rate drops sharply and the penalty is very small, the value of options will increase, and the emergence of prepayment behavior will make banks face losses.

Fixed rate loan is when the interest rate drops, the borrower prepays in order to reduce the interest expense. However, for floating rate loans, prepayment occurs when the interest rate rises. In a channel of interest rate rise, the loan interest rate will be priced according to the higher interest rate of the next period, so the borrower will choose prepayment when the funds are abundant. Whether it is a floating rate loan or a fixed rate loan, prepayment will reduce the interest income of the bank and increase the risk faced by the bank.

The same is true of bank's liability business, which mainly includes all kinds of deposit business. According to whether it can be withdrawn at any time, bank deposits can be divided into time deposits and current deposits. The current deposit is mainly for the borrower to meet the daily liquidity, which can be withdrawn at any time. The interest rate of current deposit is generally low, and its duration is short. The nature of embedded option in current deposit is not obvious, and its sensitivity to interest rate is low. Time deposit is different, and its duration and interest rate sensitivity are greater and vulnerable to changes in interest rates. With the method of financial engineering, time deposit can be decomposed into the combination of securities and options without options. If time deposit is compared with a kind of securities, then the bank can be regarded as the issuer of securities (time deposit) and options, and the depositor is equivalent to the purchaser of securities (time deposit) and options, as shown in Figure 2. The value of options will determine the motivation of depositors to withdraw in advance.

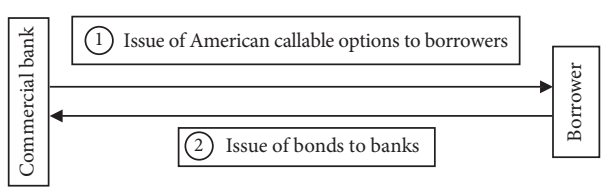

FIgURE 1: The decomposition of bank loan with embedded option.

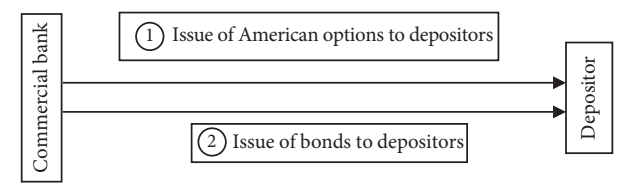

Figure 2: The decomposition of bank deposits with embedded option.

From the above analysis, we can see that the main assets and liabilities of commercial banks have the nature of embedded options. Bank deposits and loans with embedded options can be regarded as the combination of deposits loans without embedded options and options. As shown in Table 1 , the value of deposits with embedded option is equal to the value of deposits without embedded option plus the value of call options; the value of loans with embedded option is equal to the value of loans without embedded option minus the value of American call options.

\subsection{Analysis of the Exercise Boundary and Characteristics of Embedded Options in Deposits and Loans}

\subsubsection{Analysis of the Implementation and Related Charac-} teristics of Embedded Options in Deposits

Theorem 1. For depositors, time deposits can be decomposed into a fixed debt and several American interest rate call option bulls; for banks, time deposits can be decomposed into a fixed debt and several American interest rate call option bulls.

Suppose at 0 , a depositor deposits a time deposit with a maturity of $T$ in the bank, the continuous compound interest rate is $r_{0, T}$ and the deposit amount is standardized to 1 . If the withdrawal in advance does not occur, the final income of the deposit is $e^{r_{0, T} T}$. Assuming that the investor's investment period is from 0 to $T$, the depositor's goal is to maximize the return from 0 to $T$.

Suppose at time $t$, the central bank suddenly announced to change the level of deposit interest rate, the changed current interest rate is $r_{t, t}$ and the fixed deposit interest rate from $T$ to $t$ period is $r_{t, T}$. At this point,

If $e^{r_{0, T} T} \geq e^{r_{t, t} t+r_{t, T}(T-t)}$, the income from maintaining the original time deposit exceeds the transferred deposit, and the depositor chooses to maintain the original time deposit.

If $e^{r_{0, T} T} \leq e^{r_{t, t} t+r_{t, T}(T-t)}$, the income of withdrawal and deposit in advance exceeds that of maintaining the original time deposit, and the depositor chooses to withdraw and deposit in advance, and the amount of deposit in advance is $e^{r_{t, t} t}$.

To sum up, at the moment, the depositor's final income function can be expressed as follows: 
Table 1: Decomposition of bank deposits and loans with embedded options.

\begin{tabular}{|c|c|}
\hline Banking items & Corresponding bond position \\
\hline Bank deposits & Callable bonds issued by banks (short) $=$ ordinary bonds + resale right \\
\hline Bank loans & Redeemable bonds issued by borrowers $($ long $)=$ ordinary bonds - redemption right \\
\hline
\end{tabular}

In formula (1), $e^{r_{0, T} T}$ is a basic bond contract, and $e^{r_{0, T} T} \max \left[r_{t, t} t+r_{t, T}(T-t)-r_{0, T} T, 0\right]$ is an interest rate call option with an exercise price of $K=r_{0, T} T[25,26]$. The conditions for the exercise of the option are as follows:

$$
r_{t, t} t+r_{t, T} \geq r_{0, T} T \text {. }
$$

By transforming formula (2), we get the following results:

$$
\frac{r_{t, t} t+r_{t, T}}{T} \geq r_{0, T}
$$

In addition, after the option is exercised, the depositor obtains a fixed deposit with a term of $T-t$ and naturally obtains an option, that is to say, during the $T-t$ period, the depositor can withdraw and deposit in advance, and the exercise price of the option is $r_{t, T}$. Therefore, for depositors, a time deposit can be decomposed into a basic debt and several American options. However, as time goes on, the possibility of the option being executed gradually decreases, and its value gradually decreases. The value of embedded options in time deposits is reflected in a period of time shortly after the contract is signed.

Corollary 1. The necessary condition for option execution is the rise of interest rate.

Proof. The conditions of option execution are as follows:

$$
\begin{aligned}
& r_{t, t} t+r_{t, T} \geq r_{0, T} T, \\
& r_{t, T} \geq \frac{r_{0, T} T-r_{t, t} t}{T-t} .
\end{aligned}
$$

Because under normal conditions $r_{t, t} \leq r_{0, T}$,

$$
r_{t, T} \geq \frac{r_{0, T} T-r_{t, t} t}{T-t} \geq \frac{r_{0, T} T-r_{0, T} t}{T-t}=r_{0, T} .
$$

In other words, the depositor's immediate income is negative, which needs to be compensated by the future excess income.

Corollary 2. The more the interest rate rises, the more likely it is to withdraw in advance.

Proof. The more the interest rate rises, the less the immediate loss of early withdrawal and the more the excess income in the future, so the more likely the future income is to make up for the immediate loss, the more likely it is to withdraw in advance.

Corollary 3. The larger the $t$, the less likely it is to withdraw in advance.

Proof. The condition of option execution is as follows:

$$
r_{t, T} \geq \frac{r_{0, T} T-r_{t, t} t}{T-t} \geq \frac{\left(r_{0, T}-r_{t, t}\right) t}{T-t}+r_{0, T} .
$$

Therefore, the minimum executive interest rate is $r(t)=\left(\left(r_{0, T}-r_{t, t}\right) t /(T-t)\right)+r_{0, T}$.

Because $(\partial r(t) / \partial t)=\left(\left(r_{0, T}-r_{t, t}\right) T /(T-t)^{2}\right) \geq 0$, the minimum exercise interest rate level increases with the extension of time, and the possibility of option execution also decreases.

\subsubsection{Analysis on the Execution and Related Characteristics of Embedded Options in Loans}

Theorem 2. For the borrower, the loan can be decomposed into a basic debt and several American interest rate put options; for the lending bank, the loan can be divided into a basic creditor's right and several short positions of American interest rate put options.

Suppose at time 0 , an investor signs a loan contract with a bank with a term of $T$, the interest rate of the continuous compound interest loan is $r_{0, T}$, the loan amount is standardized as 1 , and the penalty is $\alpha$. If there is no prepayment, the total cost he has to pay at the end of the period is $e^{r_{0, T} T}$. Assuming that the borrower's borrowing period is constant from 0 to $T$, the goal is to minimize the cost of the period. The credit rating of the borrower has not changed during the term of the loan.

Suppose at time $t$, the central bank suddenly announced to change the interest rate level, and the interest rate of the loan with a term $T-t$ is $r_{1, T}$, then if $e^{r_{0, T} T} \geq\left(e^{r_{0, T} t}+\alpha\right) e^{r_{1 T}(T-t)}$, the cost of maintaining the loan exceeds prepayment, payment of liquidated damages, and signing a new contract, and the borrower will choose prepayment, payment of liquidated damages, and signing a new contract, and the loan amount of the new contract is $e^{r_{0, T} t}+\alpha$; if $e^{r_{0, T} T} \leq\left(e^{r_{0, T} t}+\alpha\right) e^{r_{1 T}(T-t)}$, the cost of maintaining the original term loan is lower than prepayment, 
paying liquidated damages, and signing a new contract, and the borrower maintains the original loan contract.
To sum up, at time $t$, the borrower's final cost function can be expressed as follows:

$$
\begin{aligned}
-\min \left(\left(e^{r_{0, T} t}+\alpha\right) e^{r_{1 T}(T-t)}, e^{r_{0, T} T}\right) & =-e^{r_{0, T} T}-\min \left(\left(e^{r_{0, T} t}+\alpha\right) e^{r_{1 T}(T-t)}-e^{r_{0, T} T}, 0\right) \\
& =-e^{r_{0, T} T}+\max \left(e^{r_{0, T} T}-\left(e^{r_{0, T} t}+\alpha\right) e^{r_{1 T}(T-t)}, 0\right) .
\end{aligned}
$$

In formula (7), $-e^{r_{0, T} T}$ represents a basic debt contract with credit risk.

And $\max \left(e^{r_{0, T} T}-\left(e^{r_{0, T} t}+\alpha\right) e^{r_{1 T}(T-t)}, 0\right)$ represents an interest rate put option with an exercise price of $K=e^{r_{0, T} T}$. The conditions of option execution are as follows:

$$
\begin{aligned}
e^{r_{0, T} T} & \geq\left(e^{r_{0, T} t}+\alpha\right) e^{r_{1 T}(T-t)}, \\
r_{1, T} & \leq \frac{\left[r_{0, T} T-\ln \left(e^{r_{0, T} t}+\alpha\right)\right]}{T-t} .
\end{aligned}
$$

Corollary 4. The necessary condition of option execution is the reduction of interest rate.

Proof. The conditions of option execution are as follows:

$$
e^{r_{0, T} T} \geq\left(e^{r_{0, T} t}+\alpha\right) e^{r_{1 T}(T-t)}
$$

If the interest rate increases, then $r_{t, T} \geq r_{0, T}$, and then $e^{r_{0, T} T} \leq e^{r_{0, T}+r_{t, T}(T-t)}<\left(e^{r_{0, T} t}+\alpha\right) e^{r_{1 T}(T-t)}$, and the option will not be executed, expressed mathematically as follows:

$$
r_{1, T} \leq \frac{\left[r_{0, T} T-\ln \left(e^{r_{0, T} t}+\alpha\right)\right]}{T-t}<\frac{r_{0, T} T-r_{0, T} t}{T-t}=r_{0, T} .
$$

That is to say, for the borrower, the execution of options leads to a fine, which needs to be made up by the reduction of future interest.

Corollary 5. The larger the $\alpha$, the less likely the option will be executed.

Proof. The highest interest rate of option execution is

$$
\begin{gathered}
r=\frac{\left[r_{0, T} T-\ln \left(e^{r_{0, T} t}+\alpha\right)\right]}{T-t}, \\
\frac{\partial r}{\partial \alpha}=-\frac{1}{\left(e^{r_{0, T} t}+\alpha\right)(T-t)}<0 .
\end{gathered}
$$

Therefore, the larger the $\alpha$ is, the lower the interest rate is needed before the option can be executed.

Corollary 6. The larger the $t$ is, the less likely the prepayment is.

Proof. The highest interest rate of option execution is

$$
\begin{aligned}
r & =\frac{\left[r_{0, T} T-\ln \left(e^{r_{0, T} t}+\alpha\right)\right]}{T-t}, \\
\frac{\partial r}{\partial t} & =\frac{-\ln \left(e^{r_{0, T} t}+\alpha\right)}{(T-t)^{2}}<0 .
\end{aligned}
$$

After the option is executed, the borrower can reapply for a loan with a term of $T-t$ and naturally get another option; that is, it can prepay, pay liquidated damages, and sign a new contract during the period of $T-t$. The execution price is $e^{r_{1 T}(T-t)}$. Therefore, for borrowers, a term loan can be decomposed into a basic debt and several American options. With the delay of time, the possibility of the option being executed is gradually reduced, and its value is gradually reduced. The value of embedded options in loans is reflected in a period of time shortly after the contract is signed.

3.3. The Mechanism of the Effect of Embedded Options on the Value of Bank Deposits and Loans. Loan is the main part of commercial bank's assets, and time deposit is the main part of commercial bank's liabilities. Therefore, when the loan of commercial bank can be paid in advance and the time deposit can be withdrawn in advance, that is, embedded option is implied in assets and liabilities, the value of commercial bank's assets and liabilities will be affected by the existence of embedded option. Especially when the market interest rate changes, the duration and convexity of assets and liabilities will change their original characteristics because of the existence of embedded options. This paper uses the graph to illustrate [27].

For asset items whose main part is loans, especially fixed rate loans, the rise of interest rate has no effect on them. However, when the interest rate falls below $R^{*}$, the borrowers execute the embedded options and choose to prepay, and the absolute value of asset duration becomes smaller. When the interest rate falls to a certain extent, a large area of borrowers will prepay. This makes the duration of assets further smaller and the convexity becomes negative, which is reflected in the value-interest rate curve of assets in Figure 3; that is, the curve just begins to become flat until it bends in the opposite direction, which means that the value of assets just begins to rise with the decline of interest rate, but the further decline of interest rate will lead to the borrower's exercise of rights and the bottleneck of the rise of asset value, with the upper limit of $P^{*}$; for the liability items whose main part is time deposit, the decrease in interest rate has no effect on them. However, when the interest rate rises above $R^{*}$, the depositor executes the embedded options and chooses to withdraw in advance, which leads to the decrease in the 


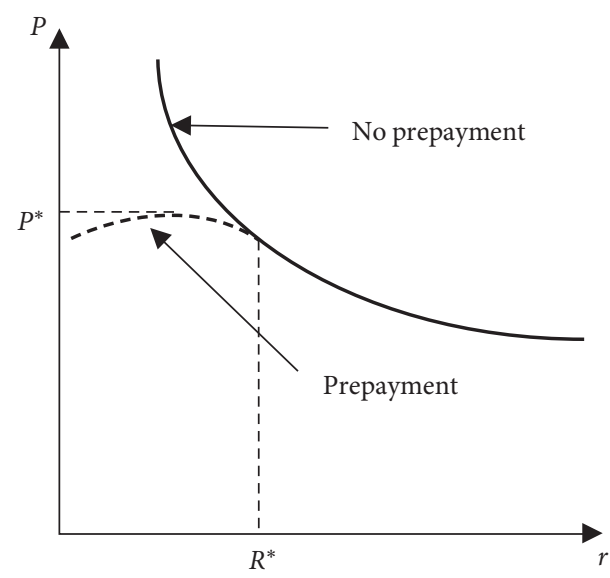

Figure 3: Value-interest rate curve of assets.

absolute value of the duration of the liability, which is reflected in the value-interest rate curve of the liability in Figure 4; that is, the curve becomes flat. This means that the value of the liability has a lower limit as interest rates rise.

In order to more clearly explain the impact of the existence of embedded options on the net assets (the difference between assets and liabilities) of commercial banks, this paper uses the mathematical expression of net assets and the value-interest rate curve of assets and liabilities to explain in more detail. Usually, in order to prevent interest rate risk exposure, commercial banks match the duration convexity of asset items and liability items to make the slope of valueinterest rate curve of asset and liability the same. Here, bank assets are represented by $A$, liabilities by $L$, and net assets by $E$. Then, $\mathrm{d} E=\mathrm{d} A-\mathrm{d} L$. The derivative of this method is as follows:

$$
\begin{gathered}
\mathrm{d} A=\frac{\mathrm{d} A}{\mathrm{~d} R_{A}} \mathrm{~d} R_{A}+\frac{1}{2} \frac{\mathrm{d}^{2} A}{\mathrm{~d} R_{A}^{2}}\left(\mathrm{~d} R_{A}\right)^{2}, \\
\mathrm{~d} L=\frac{\mathrm{d} L}{\mathrm{~d} R_{L}} \mathrm{~d} R_{L}+\frac{1}{2} \frac{\mathrm{d}^{2} L}{\mathrm{~d} R_{L}^{2}}\left(\mathrm{~d} R_{L}\right)^{2} .
\end{gathered}
$$

Let $A$ and $L$ have the same initial interest rate, $R_{A}=R_{L}=R$, and $\mathrm{d} R_{A}=\mathrm{d} R_{L}=\mathrm{d} R$. We can get $D_{A}=-(\mathrm{d} A / A \mathrm{~d} R), \quad D_{L}=-(\mathrm{d} L / L \mathrm{~d} R), C_{A}=-\left(\mathrm{d}^{2} A / A \mathrm{~d} R^{2}\right)$, and $C_{L}=-\left(\mathrm{d}^{2} L / L \mathrm{~d} R^{2}\right)$, and then the $\mathrm{d} E$ expression is as follows:

$$
\mathrm{d} E=-\left(D_{A}-K D_{L}\right) A \mathrm{~d} R+\frac{1}{2}\left(C_{A}-K C_{L}\right) A(\mathrm{~d} R)^{2} .
$$

In equation (14), $D_{A}$ is the duration of assets, $D_{L}$ is the duration of liabilities, $C_{A}$ is the convexity of assets, and $C_{L}$ is the convexity of liabilities. $K=L / A$ is the ratio of assets to liabilities, also known as leverage. $D_{\mathrm{GAP}}=D_{A}-K D_{L}$ can reflect the duration matching of assets and liabilities, which is called duration gap; $C_{\mathrm{GAP}}=C_{A}-K C_{L}$ can reflect the convexity matching of assets and liabilities, which is called convexity gap. From the expression of formula (14), we can know that the main factors affecting the net assets of

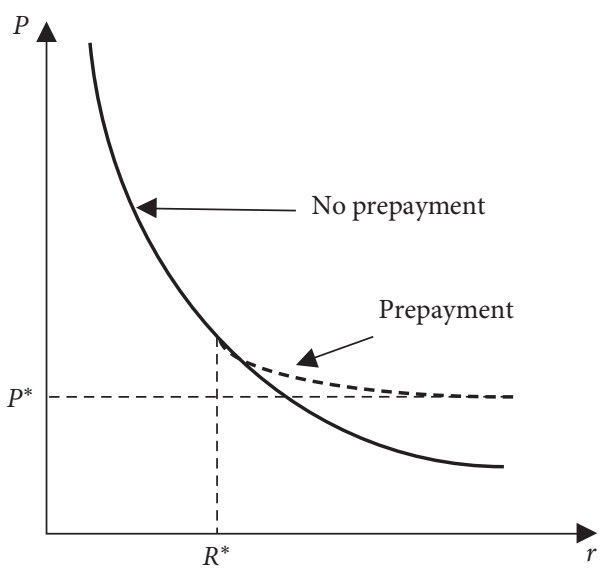

FIGURE 4: Value-interest rate curve of liabilities.

commercial banks are $A, \quad D_{\mathrm{GAP}}=D_{A}-K D_{L}$, $C_{\mathrm{GAP}}=C_{A}-K C_{L}$, and $R$ [28-30].

Next, we use the value-interest rate curve of bank assets and liabilities in Figure 5 to illustrate the impact on the bank's net assets when the asset liability items are implied with embedded options. Assume that the initial net assets of the bank are greater than zero, so the value-interest rate curve of the assets is above the value-interest rate curve of the liabilities. At the beginning, without considering the existence of embedded options, commercial banks have matched the duration and convexity of assets and liabilities. When the interest rate changes little, that is, between $R^{*}$ and $R^{* *}$, the effect of asset liability management is very good, the net assets remain stable, and there is no interest rate risk exposure. However, when the interest rate falls below $R^{* *}$, the depositors will not be affected, the borrowers will repay in advance, and the net assets will begin to decline, especially when the interest rate falls below $R_{1}$, the net asset is $E_{1}$, significantly less than the initial net assets $E^{*}$; similarly, when the interest rate rises to $R^{*}$, the lender will not be affected, and the depositor withdraws the deposit in advance, especially when the interest rate rises to $R_{2}$, the net assets of the bank become $E_{2}$, significantly less than the initial net assets $E^{*}[31]$.

If we analyze formula (14), when the interest rate falls further below $R^{* *}$, the duration gap $D_{\mathrm{GAP}}=D_{A}-K D_{L}$ changes from 0 to negative and the convexity gap $D_{\mathrm{GAP}}=$ $D_{A}-K D_{L}$ also changes from 0 to negative so that the net assets become smaller; when the interest rate rises above $R^{*}$, the duration gap $D_{\mathrm{GAP}}=D_{A}-K D_{L}$ changes from 0 to positive and the convexity gap $D_{\mathrm{GAP}}=D_{A}-K D_{L}$ changes from 0 to negative, so the net assets become smaller. That is to say, as long as the bank's loan can be repaid in advance and the time deposit can be withdrawn in advance, that is, when the bank's asset liability project is implied with embedded options, the net assets will be less no matter whether the interest rate rises or falls. However, commercial banks ignore this kind of embedded option with intrinsic value, which leads to that the real interest rate difference between deposit and loan is not the difference between loan interest rate and deposit interest rate on the surface, which leads to 


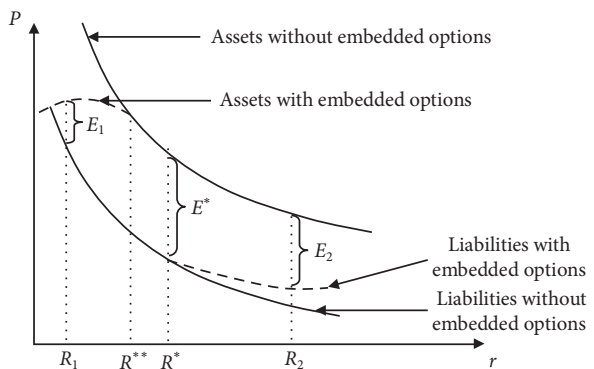

FIgURE 5: Value-interest rate curve of bank assets and liabilities.

the hidden interest loss of commercial banks, and the difficulty of interest rate risk management will increase.

\section{Selection of Interest Rate Model and Estimation of Model Parameters}

4.1. Selection of Interest Rate Model. Embedded option is an interest rate derivative, so it is particularly important to describe the trend of interest rate. This paper combines the interest rate jump behavior caused by macro policy with the interest rate diffusion behavior caused by market behavior and chooses the CIR model with jump term to describe the change path of deposit and loan interest rate, in which the jump term can represent the sudden change of policy, the collapse of stock market, and the administrative control of interest rate [32].

The CIR model considers that in a risk neutral world, the change of short-term interest rate follows the following order:

$$
\mathrm{d} r=\alpha(\beta-r) \mathrm{d} t+\sigma r^{1 / 2} \mathrm{~d} W_{t} .
$$

In equation (15), $r$ represents the short-term instantaneous interest rate; $\alpha, \beta$, and $\sigma$ represent the average recovery speed of interest rate, the long-term average of interest rate, and the volatility of interest rate, respectively, and they are all constants. $W_{t}$ is Brownian motion. In this paper, the jump term $J \mathrm{~d} P$ is added to the CIR model, which is the jumpdiffusion model. Its expression is as follows:

$$
\mathrm{d} r(t)=\alpha\left(\beta-r_{t}\right) \mathrm{d} t+\sigma(t) r^{1 / 2} \mathrm{~d} W_{t}+J \mathrm{~d} P .
$$

In equation (16), $J$ represents a random variable with uniform distribution. In order to avoid the sudden depth jump causing negative interest rate, it is assumed that $J$ follows the uniform distribution on $(m, n)$, and $\mathrm{d} P$ represents the Poisson distribution with jump intensity $\lambda$ [33-35].

4.2. Estimation Method of Model Parameters. In the jumpdiffusion model, Jis completely independent of parameters $\alpha, \beta, \sigma$, and $\lambda$. Starting from the practicability and simplicity of parameter estimation, this paper calculates the existing interest rate data by Excel tool, obtains its parameters $\alpha, \beta, \sigma$, and $\lambda$, and uses the maximum likelihood estimation method to estimate the parameters $(m, n)$ in $J$.

4.2.1. Estimation Method of Basic Parameters $\alpha, \beta, \sigma$, and $\lambda$. The estimation methods of basic parameters $\alpha, \beta, \sigma$, and $\lambda$ are shown in Table 2 .

4.2.2. Estimation Method of Parameter ( $\mathbf{m}, \mathbf{n})$ in Uniform Distribution J. The maximum likelihood estimation (MLE) method is used to estimate the jump parameters. The MLE method is a widely used method for estimating values. It is based on the maximum likelihood principle; that is, there are several possible results $A, B$, and $C$, in a random experiment. If result $A$ appears in an experiment, it can be considered that $p(A)$ is larger. The principle is as follows.

Let the family of probability functions of population $\xi$ be $\{f(x ; \theta), \theta \in \Theta\}$, where $\theta^{\prime}=\left(\theta_{1}, \theta_{2}, \ldots, \theta_{k}\right)$ is the parameter vector to be estimated in $K$ dimension and $\left(x_{1}, \ldots, x_{n}\right)=x$ is an observed value of subsample $\left(\xi_{1}, \ldots, \xi_{n}\right)=\xi^{\prime}$, then the probability of subsample $\xi$ falling into the field of point $x^{\prime}$ is $\prod_{i=1}^{n} f\left(x_{i}, \theta\right) \Delta x_{i}$. It can be seen that this probability will be affected by the change of $\theta$, which is the function of $\theta$. The principle of the maximum likelihood method is to select the parameter value $\widehat{\theta}$ which makes the probability $\prod_{i=1}^{n} f\left(x_{i}, \theta\right) \Delta x_{i}$ of the subsample in the field of observation value $\left(x_{1}, \ldots, x_{n}\right)$ reach the maximum as the estimation of $\theta$. That is to say, for a fixed $\left(x_{1}, \ldots, x_{n}\right), \widehat{\theta}$ is selected.

$$
\prod_{i=1}^{n} f\left(x_{i} ; \widehat{\theta}\right)=\underset{\theta \in \Theta}{\operatorname{SU}} P \prod_{i=1}^{n} f\left(x_{i} ; \theta\right) .
$$

Based on the above principle, we discretize equation (16) by Euler as follows:

$$
r_{t}-r_{t-1}=\alpha\left(\beta-r_{t-1}\right)+\varepsilon_{t} .
$$

Then, we define the parameter vector to be estimated $\theta=[\alpha, \beta, \sigma, m, n, q]$, where $m$ and $n$ are the mean distribution parameters of the jump process and are the parameter values to be determined in our method; $\alpha, \beta, \sigma$, and $q$ represent the mean recovery speed of the jump-diffusion model, the long-term mean of interest rate, and volatility and jump frequency, respectively, which can be determined in the above parameter estimation methods. Suppose when the jump occurs, i.e., $\mathrm{d} p=1, \quad E\left(\varepsilon_{t}\right)=(m+n) / 2$ and $D\left(\varepsilon_{t}^{2}\right)=\sigma^{2} r_{t-1}+\left((n-m)^{2} / 12\right)$; when the jump does not occur, i.e., $\mathrm{d} p=0, E\left(\varepsilon_{t}\right)=0$ and $D\left(\varepsilon_{t}^{2}\right)=\sigma^{2} r_{t-1}$.

If the probability of jump is $q=\lambda \mathrm{d} t$, the transition probability density of jump diffusion is approximately as follows: 
TABle 2: Estimation method of basic parameters.

\begin{tabular}{|c|c|c|}
\hline Parameter & Calculation formula & Illustration \\
\hline$\alpha$ & $y=\alpha t+\varepsilon$ & $\begin{array}{l}\text { First, the standard deviation of each term is calculated through the interest rate data, and then the } \\
\text { straight line reflecting the relationship between the standard deviation and the term, and it can be } \\
\text { obtained by linear regression. The slope of the straight line is } \alpha \text {. }\end{array}$ \\
\hline$\beta$ & $\beta=(1 / n) \sum_{i=1}^{n} R_{i}$ & $\begin{array}{l}\text { The long-term average can be replaced by the average interest rate over the years, where } R_{i} \text { is the } \\
\text { historical data value of the corresponding term interest rate. }\end{array}$ \\
\hline$\sigma$ & $\sigma=\sqrt{(1 / n) \sum_{i=1}^{n}\left(R_{i}-\beta\right)^{2}}$ & $\begin{array}{l}\text { We usually use the volatility of the base market interest rate to replace the transient interest rate } \\
\text { volatility } \sigma \text {, which can be expressed by the standard deviation of interest rate in period } N \text {, where } R_{i} \\
\text { and } \beta \text { have the same meaning as above. }\end{array}$ \\
\hline$\lambda$ & $\lambda=w / n$ & $\begin{array}{l}\lambda \text { is equal to the average number of events per unit time, where } w \text { is the number of interest rate } \\
\text { jumps, } n \text { is the interval length, and its unit is month. }\end{array}$ \\
\hline
\end{tabular}

$$
\begin{aligned}
f\left(r_{t} \backslash r_{t-1} ; \theta\right)= & q \frac{1}{\sqrt{2 \pi\left(\sigma^{2} r_{t-1}+\left((n-m)^{2} / 12\right)\right)}} \exp \left(-\frac{\left(r_{t}-r_{t-1}-\alpha \beta+\alpha r_{t-1}-((m+n) / 2)\right)^{2}}{2\left(\sigma^{2} r_{t-1}+\left((n-m)^{2} / 12\right)\right)}\right) \\
& +(1-q) \frac{1}{\sqrt{2 \pi\left(\sigma^{2} r_{t-1}\right)}} \exp \left(-\frac{\left(r_{t}-r_{t-1}-\alpha \beta+\alpha r_{t-1}\right)^{2}}{2\left(\sigma^{2} r_{t-1}\right)}\right) .
\end{aligned}
$$

From the stationarity and Markov property of Poisson process, the likelihood function is obtained:

$$
l(\theta)=\prod_{i=1}^{n} f\left(r_{t} \backslash r_{t-1} ; \theta\right) .
$$

The likelihood function $l(\theta)$ is logarithm. The results are as follows:

$$
L(\theta)=\sum_{i=1}^{n} \ln f\left(r_{t} \backslash r_{t-1} ; \theta\right) .
$$

In order to obtain the maximum value of equation (21), let the likelihood equation be as follows:

$$
\frac{\partial L(\theta)}{\partial \theta_{j}}=0, \quad j=1,2 .
$$

The parameter values of MLE can be obtained by solving and verifying whether it is the maximum point $[36,37]$.

\subsection{Empirical Analysis of Model Parameters}

4.3.1. Parameter Empirical Simulation. The choice of interest rate data follows the principle of trading volume, stability, and relevance. Considering the timeliness of the data, this paper only selects the benchmark interest rate of deposits and loans published by the people's Bank of China for the last 20 years, that is, 240 months from January 1, 2001, to January 1, 2021.

(1) Long-Term Return Average of Interest Rate $\alpha$. By linear regression of the data in Table 3, we can get the slope of the curve of volatility and maturity, which is the long-term return mean of interest rate $\alpha$. The results of EViews regression are shown in Figure 6. The linear function is as follows:

$$
y=0.0005 x+0.0062
$$

According to equation (23), the parameter $\alpha=0.0005$.

(2) Long-Term Average Interest Rate $\beta$. Using the parameter estimation method in Table 2, the results of $\beta$ are shown in Table 3.

(3) Volatility $\sigma$. Using the parameter estimation method in Table 2, the results of $\sigma$ are shown in Table 4.

(4) Jump Strength $\lambda$. According to the statistics of the change times of time deposit interest rate in recent ten years, the jump times of time deposit interest rate of each term are shown in Table 5.

Since the monthly data are 240 , the corresponding $\lambda$ value can be obtained by dividing the number of jumps by 240. The results of $\lambda$ are shown in Table 6 .

(5) Estimation of Parameter $(\mathbf{m}, \mathbf{n})$ in Mean Distribution J. Taking the 5-year fixed deposit as an example, the maximum likelihood method is used to calculate with MATLAB. The deviation less than $10^{-7}$ is taken as the standard to estimate the parameters, and the result shows that $m=-0.016$ and $n=0.016$.

After estimating all the model parameters, we can find that the interest rate of five-year fixed deposit follows a stochastic process:

$$
\mathrm{d} r(t)=0.0005\left(0.0473-r_{t}\right) \mathrm{d} t+0.00826 \sqrt{r_{t}} \mathrm{~d} w_{t}+J \mathrm{~d} p .
$$

The model of equation (24) is discretized, and the results are as follows:

$$
\begin{aligned}
R_{t+1}= & R_{t}+0.00050\left(0.0473-R_{t}\right) \Delta t \\
& +0.00826 \sqrt{R_{t}} \mathrm{~d} w_{t}+J \mathrm{~d} p .
\end{aligned}
$$

In equation (25), $J$ follows the mean distribution of $(-0.016,0.016)$ and $\mathrm{d} P$ represents the Poisson distribution of jump intensity $\lambda=0.104$. 
TABle 3: Average interest rate of time deposit of each term.

\begin{tabular}{lccccrrr}
\hline Interest rate varieties & Current & 3 months & 6 months & 1 year & 2 year & 3 year & 5 year \\
\hline$\beta$ & 0.0052 & 0.0225 & 0.0256 & 0.0283 & 0.0347 & 0.0408 & 0.0473 \\
\hline
\end{tabular}

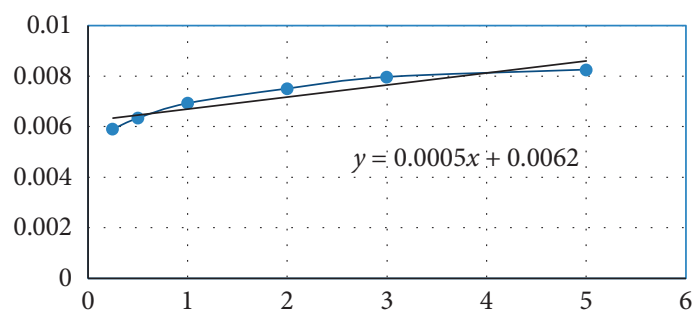

FIgURE 6: EViews regression results.

TABLE 4: Time deposit interest rate volatility of each term.

\begin{tabular}{lccccccc}
\hline Interest rate varieties & Current & 3 months & 6 months & 1 year & 2 year & 3 year & 5 year \\
\hline$\sigma$ & 0.00189 & 0.00591 & 0.00634 & 0.00693 & 0.00751 & 0.00797 & 0.00826 \\
\hline
\end{tabular}

TABLE 5: Jump times of time deposit interest rate of each term.

\begin{tabular}{lccccccc}
\hline Interest rate varieties & Current & 3 months & 6 months & 1 year & 2 year & 3 year & 5 year \\
\hline Hop count & 14 & 22 & 25 & 26 & 26 & 25 & 25 \\
\hline
\end{tabular}

TABle 6: Jump intensity of time deposit interest rate of each term.

\begin{tabular}{lccccccc}
\hline Interest rate varieties & Current & 3 months & 6 months & 1 year & 2 year & 3 year & 5 year \\
\hline$\lambda$ & 0.0583 & 0.0917 & 0.104 & 0.108 & 0.107 & 0.104 & 0.104 \\
\hline
\end{tabular}

Using the same parameter estimation method and the same interval of loan interest rate, we estimate the jumpdiffusion model of 10-year loan interest rate as follows:

$$
\begin{aligned}
R_{t+1}= & R_{t}+0.00054\left(0.0692-R_{t}\right) \Delta t \\
& +0.00947 \sqrt{R_{t}} \mathrm{~d} w_{t}+J \mathrm{~d} p .
\end{aligned}
$$

In equation (26), $J$ follows the mean distribution of $(-0.014,0.014)$ and $\mathrm{d} P$ represents the Poisson distribution of jump intensity $\lambda=0.104$.

\subsubsection{Empirical Test of the Model}

(1) The Process of Empirical Test. Taking the five-year deposit interest rate as an example, this paper tests the model from the aspects of mean reversion, volatility, and jump and compares the CIR model with jump term and the CIR model without jump term with the selected interest rate sample data to analyze the standard error of the two models. The specific process is as follows:

Firstly, the sample path of the underlying variable in the validity period is simulated under the risk neutral measure.
The discrete stochastic model has been given in the previous paper:

$$
R_{t+1}=R_{t}+0.00050\left(0.0473-R_{t}\right) \Delta t+0.00826 \sqrt{R_{t}} \mathrm{~d} w_{t}+J \mathrm{~d} p .
$$

In equation (27), $R_{t}$ is the existing five-year fixed deposit interest rate of $0.0275 ; \Delta t$ is $1 / 12$; Brownian motion $\mathrm{d} w_{t}$ can be expressed by $\sqrt{\Delta t} Z$, where $Z \sim N(0,1)$ normal distribution can realize the sample sampling of standard normal distribution in MATLAB; $J$ and $\mathrm{d} P$ can be completed by the identification sampling of commands in MATLAB.

Secondly, the corresponding function values on the sample path are estimated. According to the properties of the underlying variables, the absolute value of the deviation between the simulated data and the real data on each sample path is estimated:

$$
d_{i}=\left|R_{i m}-R_{i s}\right|
$$

In equation (28), $R_{i m}$ is the simulated value of interest rate and $R_{i s}$ is the real data of interest rate.

Finally, the estimated value of the underlying variable is estimated. The estimated value of the underlying variable is 
obtained by averaging the corresponding function values on the simulated sample path:

$$
d=\frac{1}{N} \sum_{i=1}^{N} d_{i}
$$

In this paper, the Monte Carlo simulation method is used to simulate the interest rate model for many times to test the mean reversion of the model, the rationality of the limit value, and the error comparison between the diffusion model and the jump-diffusion model.

(2) Empirical Test Result

From the two results in Figure 8, we can see that the corresponding error value of the jump-diffusion model is 0.0417 and the corresponding error value of the interest rate model without jump term is 0.0462 . Therefore, it can be seen that the jump-diffusion model is more in line with the trend of China's benchmark deposit and loan interest rate.

\section{Pricing of Embedded Options of Deposits and Loans Based on Monte Carlo Simulation}

\subsection{Application of Monte Carlo Simulation in Option Pricing}

5.1.1. Analysis of the Optimal Execution Strategy of Embedded Options. Before analyzing and pricing the embedded option, it is regarded as a standard American option, and the embedded option has the characteristics of early execution. The standard of early execution is that the value obtained by executing the option is greater than or equal to the value obtained by not executing in advance. Because the embedded option has a strong path dependence, it will have a different value because of the different interest rate changes, so there may be many opportunities for early execution in the duration of the option, but only one time is optimal, making the value of the option maximum, and the value at this time is the real value of the option. Therefore, the steps to find the optimal execution strategy are as follows:

(1)Based on the change of interest rate, calculate the corresponding interest income or interest expense at each time point. For deposits, when the interest rate changes, the interest income at this time point is the sum of the demand interest before the deposit transfer point and the time deposit income after the deposit transfer point; for loans, when the interest rate changes, the interest expense at this time point is the sum of the interest expense before refinancing, the penalty for breach of contract, and the interest expense after refinancing.

(2) Optimal Execution Strategy. A point on the path of interest rate change makes the interest income maximum or the interest expense minimum, then this point is the optimal execution strategy point, and the American option value is the option value of this point.
The pricing of embedded option is to find the option value of the optimal execution strategy and discount the expected return at that time to the current time. Therefore, we can know that for a path of interest rate change, we can find the best execution strategy at each execution time from the back to the front. Through repeated deduction, we finally get the best execution strategy and the corresponding discount value of income on each path.

\subsubsection{Application of Monte Carlo Simulation}

(1) Monte Carlo Simulation Technology. The embedded option has the characteristics of multidimension and complexity, so the pricing method of numerical analysis is suitable. The numerical analysis model can effectively simulate various variables in reality, and this method has become an indispensable tool for embedded option valuation. The implementation of numerical analysis includes network analysis and Monte Carlo simulation. Network analysis is not suitable for pricing embedded options. Firstly, many fundamental characteristics of embedded options cannot be described by network methods, such as the jumpdiffusion model describing the trend of interest rate change, which cannot be simulated by network methods. Secondly, for some high-dimensional weighted bonds with more underlying variables, it is impossible to price them. Thirdly, the discrete form of low dimensional equivalency is its fatal defect, that is to say, its default interest rate will only change once in the above equal time interval, while the actual situation is that the embedded option can be executed at any time before the maturity date of the option.

When the dimension of financial derivative securities is relatively high, Monte Carlo simulation technology will become the only effective numerical analysis method; that is, it can effectively solve the "dimension disaster" problem. The essence of Monte Carlo simulation is a numerical analysis method to obtain the actual estimation of the mathematical expectation of random distribution by approximately replacing the overall expectation of random distribution with the sample mean of random sampling. Sometimes, when the pricing problem of complex options cannot be solved by analytical or numerical methods, Monte Carlo simulation can obtain the interest rate path and the final profit and loss of options by inputting assumed parameters and thousands of computer simulations, then obtain the distribution of option value, and finally use the average result to calculate the price of complex options [38-40].

(2) Application of Monte Carlo Simulation Technology in Option Pricing. According to the nonarbitrage asset pricing theory, the price of financial derivative securities is the discounted expected value of its profit and loss function, and the expected value is the expected value under the risk neutral probability measure. According to the theory of probability statistics and stochastic analysis, these expected 
values can also be expressed in the form of integral in a specific region. Monte Carlo simulation is to estimate the price of financial derivative securities by simulating these mathematical expectations or integrals. The steps are as follows:

Suppose $S_{t}$ is the price of the underlying asset at time $t, r$ is the risk-free market interest rate, $\sigma$ is the volatility of the underlying asset return, $T$ is the maturity of the option, and $X$ is the exercise price of the option. Under the background of Black-Scholes, the underlying asset price $S_{t}$ satisfies the geometric Brownian motion:

$$
\mathrm{d} S_{t}=r S_{t} \mathrm{~d} t+\sigma S_{t} \mathrm{~d} W(t) .
$$

In equation (30), $W(t)$ is the geometric Brownian motion under the risk neutral probability measure, then the return function at the maturity date of the option can be expressed as follows:

$$
C=e^{-r T} E(\bar{S}-X)^{+} .
$$

$\bar{S}$ in equation (31) is the average price of the underlying asset in $(0, T)$ time.

The specific process of Monte Carlo simulation to realize option value calculation is as follows:

(1) Simulate $n$ paths of underlying asset prices and then get the average prices of each path $\overline{S_{1}}, \overline{S_{2}}, \ldots, \overline{S_{n}}$;

(2) Let $Y=E(\bar{S}-X)^{+}$, calculate the period weight of the average price on each path and get the value $Y_{1}, Y_{2}, \ldots, Y_{n}$

(3) Let $C_{j}=e^{-r T} Y_{j}, n=1,2, \ldots, n$ and average the value of $C$ to get $\bar{C}$; that is, $\bar{C}=(1 / n) \sum_{i=1}^{n} C_{j}$; this is the option value obtained by simulation.

\subsection{Pricing Steps of Embedded Options for Commercial Banks' Deposits and Loans}

5.2.1. Pricing Steps of Embedded Options in Deposits. Using Monte Carlo simulation to price the embedded options in commercial bank deposits, the steps are as follows:

(1) Simulate the Sample Path of the Underlying Variable within the Validity Period under the Risk Neutral Measure. The underlying variable here is deposit interest rate, and the interest rate model describing the change of deposit interest rate is the jump-diffusion model:

$$
\mathrm{d} r(t)=\alpha\left(\beta-r_{t}\right) \mathrm{d} t+\sigma(t) r^{1 / 2} \mathrm{~d} W_{t}+J \mathrm{~d} P .
$$

Equation (32) is discretized and simulated. Take $\Delta t=1$ month to simulate the possible path of interest rate after $n$ years $(12 * n$ months) in the current initial interest rate state. By using this simulation method repeatedly, thousands of interest rate paths can be simulated to meet the needs of Monte Carlo simulation.

(2) Calculation of Embedded Option Value on Simulation Path of Each Sample. Each interest rate sample path may involve the early withdrawal of deposits, so there may be multiple options on one interest rate path. However, based on the optimal strategy problem of American option execution, there is only one optimal execution point, and then the discount of the option value of the optimal execution point is the value of the embedded option on the interest rate path:

$$
\begin{aligned}
C= & \exp (-r t) \max \left[\exp \left(h_{0, T} \cdot t\right)\right. \\
& \left.\cdot \exp \left(R_{t, T} \cdot(T-t)\right)-\exp \left(R_{0, T} \cdot T\right), 0\right] .
\end{aligned}
$$

In equation (33), $C$ is the value of the option, $r$ is the riskfree interest rate, $R_{0, T}$ is the interest rate of the previous contract, $h_{0, T}$ is the current interest rate, $R_{t, T}$ is the interest rate after the change of time $t$, and $T$ is the deposit term.

(3) Average the Corresponding Option Values on the Simulated Sample Path. The average value of the corresponding options on the simulated sample path is obtained, and the estimated value of the embedded options in the time deposit is obtained:

$$
\bar{C}=\frac{1}{n} \sum_{i=1}^{n} C_{i} .
$$

5.2.2. Pricing Steps of Embedded Options in Loans. The pricing process of embedded options in loans is similar to the calculation process of embedded option value in time deposits; except that the penalty for prepayment is to pay liquidated damages, that is, to charge a certain proportion of liquidated damages from the prepayment loans, and the proportion coefficient is expressed by $\alpha$. From 2019, CCB's prepayment policy for housing loans is to charge $3 \%$ of prepayment for less than one year, $2 \%$ for one to two years, and $1 \%$ for more than two years.

Although the calculation of embedded options in loans is one more penalty $\alpha$ than that in deposits, the Monte Carlo simulation method can still be used, and the calculation steps are as follows:

(1) Simulate the Change Path of Loan Interest Rate. The 10year loan interest rate model is shown in formula (26).

(2) Calculation of Embedded Option Value on Simulation Path of Each Sample. Due to the existence of penalty $\alpha$, the calculation of embedded options in loans is slightly different from that in deposits:

$$
C=\exp (-r t) \max \left[\exp \left(r_{0, T} \cdot T\right)-\left(\alpha+\exp \left(r_{0, t} \cdot t\right)\right) \cdot \exp \left(r_{t, T} \cdot(T-t)\right), 0\right]
$$




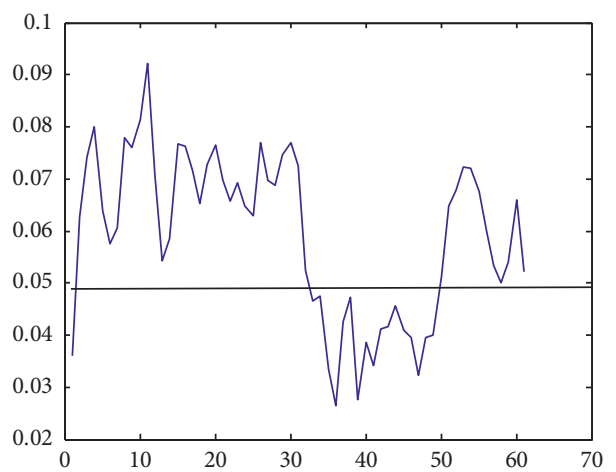

FIgURE 7: A simulated interest rate path of the jump-diffusion model.

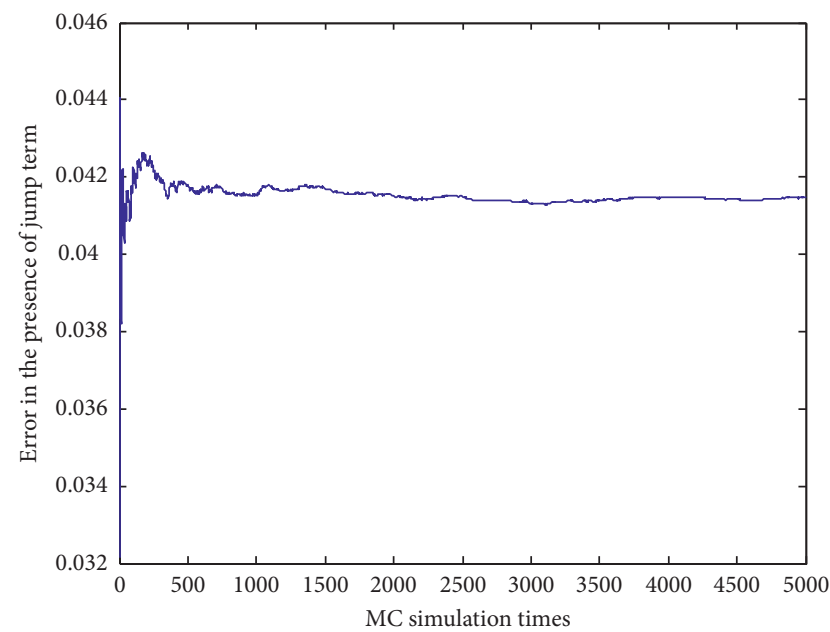

(a)

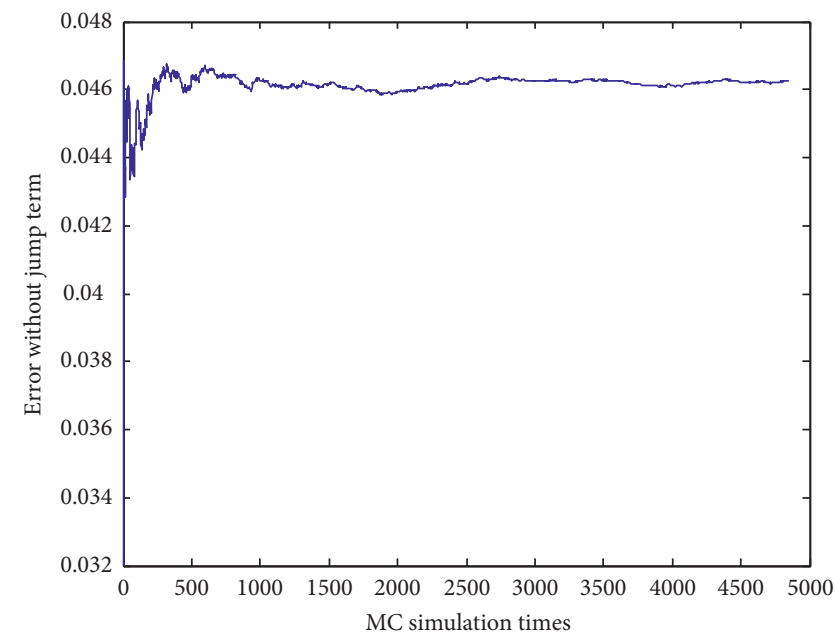

(b)

Figure 8: Comparison of simulated value error under two interest rate models: (a) in presence of jump term; (b) without jump term.

In equation (35), $C$ is the embedded option value, $r$ is the risk-free interest rate, $\alpha$ is the penalty when prepaying the loan, $t$ is the time when the option is exercised, $T$ is the loan term, $r_{0, T}$ is the interest rate agreed in the previous loan contract, and $r_{t, T}$ is the interest rate in the new loan contract signed at $t$.

(3) Average the Corresponding Option Values on the Simulated Sample Path. By averaging the corresponding options on the simulated sample path, we can get the estimated value of the embedded options in loans:

$$
\bar{C}=\frac{1}{n} \sum_{i=1}^{n} C_{i}
$$

\subsection{Pricing of Embedded Options Based on Monte Carlo Simulation}

5.3.1. An Empirical Study of Embedded Option Pricing in Deposits. We take the latest five-year fixed deposit interest rate of 0.0275 on January 1, 2021, as the initial interest rate and the one-year fixed deposit interest rate of 0.015 as the discount rate, and the deposit amount is standardized to 1, and the embedded option value is calculated in the five-year fixed deposit through simulation.

We have analyzed the selection of the interest rate model and the principle and steps of the Monte Carlo simulation method. In order to make the simulation results more accurate, we need to use MATLAB software. We know from the characteristics of Monte Carlo simulation that the accuracy of the simulation results has a great relationship with the simulation times. The more the simulation times are, the more accurate the results will be. Therefore, 100000 times of simulation are carried out here, and the simulation results are shown in Figure 9.

It can be clearly seen from the convergence chart of option value in Figure 9 that the value of embedded option in 5-year fixed deposit of commercial banks is 0.0012. In other words, the real deposit interest rate of commercial banks is 0.0012 more than the nominal deposit interest rate.

5.3.2. Empirical Analysis of Embedded Option Pricing in Loans. We take the latest 10-year loan interest rate of 0.049 on January 1, 2021, as the initial interest rate and the one- 


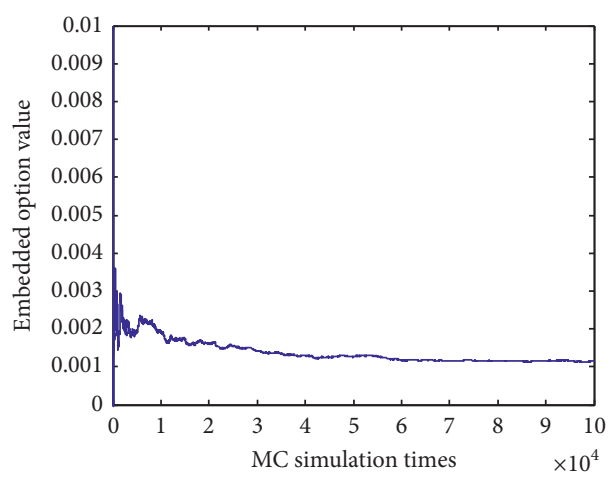

Figure 9: Simulation results of embedded option value in 5-year fixed deposit.

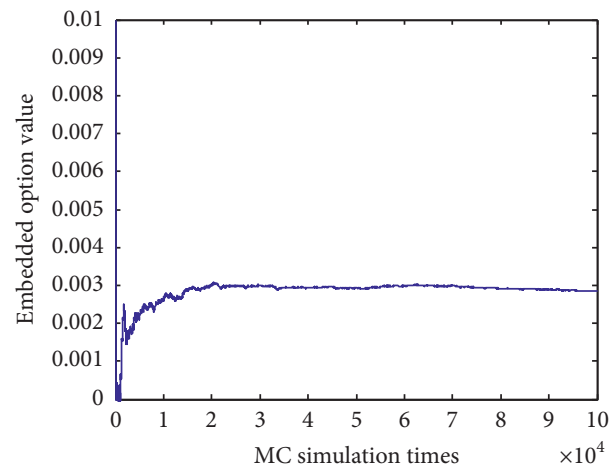

Figure 10: Simulation results of embedded option value in 10-year loan.

year fixed deposit interest rate of 0.015 as the discount rate, and the loan amount is standardized to 1. Assuming that the customer needs to pay $1 \%$ penalty for prepayment, we calculate the embedded option value in the 10 -year loan through simulation and simulate 100000 knots. The results are as follows.

It can be clearly seen from the convergence chart of option value in Figure 10 that the value of embedded option in 10-year loan of commercial bank is 0.0028. In other words, the 10-year real loan interest rate of commercial banks is 0.0028 less than the nominal loan interest rate.

\section{Conclusion}

For depositors, time deposits can be divided into a fixed claim and several American interest rate call options. The necessary condition for the execution of the embedded option in deposit is that the interest rate rises, and the more the interest rate rises, the greater the possibility of the option execution. In addition, the possibility of option execution decreases with the passage of time, generally only in the early implementation. For the borrower, the loan can be decomposed into a basic debt and several American interest rate put options. The necessary condition for the execution of embedded option in loan is that the interest rate falls, and the more the interest rate falls, the more likely the option is to be executed. The greater the penalty, the less likely the option is to be executed. The larger $t$ is, the less likely the option is to be executed, which is generally only executed in the early stage.

Interest rate is the underlying asset of embedded option; based on the in-depth study of the characteristics and movement law of interest rate, this paper obtains an interest rate model suitable for Chinese market characteristics; that is, adding jump factor to the CIR model to describe the jump of interest rate caused by government macrocontrol or market mutation, which is the jump-diffusion model. Through the Monte Carlo simulation test, the jump-diffusion model has smaller error value than the CIR model, which is more suitable to describe China's interest rate market.

Based on the jump-diffusion model of interest rate, this paper uses the Monte Carlo simulation method to analyze and price the embedded options in 5-year fixed deposit and 10-year loan. The results show that the embedded options of 5-year fixed deposit and 10-year loan are 0.0012 and 0.0028 , respectively. Bank's real deposit and loan spread $=$ (loan interest rate-American interest rate put option price)-(deposit interest rate + American interest rate call option price). Therefore, we can see that the existence of embedded options significantly reduces the bank's real deposit and loan spread.

\section{Data Availability}

No data were used to support this study. 


\section{Conflicts of Interest}

The authors declare that they have no conflicts of interest.

\section{Acknowledgments}

This work was supported by the Key Research Projects of Humanties and Social Sciences in Anhui Universities (SK2020A0405), Anhui Social Science Innovation and Development Research Project (2020ZD007), and Anhui Jianzhu University Research Startup Project (2019QDZ61).

\section{References}

[1] J.-L. Huang, "Interest rate liberalization and risk control of commercial banks," Economic Research, vol. 1, pp. 19-28, 2001, in Chinese.

[2] K. Drakos, "Assessing the success of reform in transition banking 10 years later: an interest margins analysis," Journal of Policy Modeling, vol. 25, no. 3, pp. 309-317, 2003.

[3] Z.-L. Zheng and H. Lin, "Decomposition and pricing of embedded options in assets and liabilities of bank," Financial Research, vol. 7, pp. 24-32, 2004, in Chinese.

[4] S. A. Easton, "A note on modified lattice approaches to option pricing," Journal of Futures Markets, vol. 16, no. 5, pp. 585-594, 1996.

[5] J. H. Gilkeson and C. K. Ruff., "Valuing the withdrawal option in retail CD portfolios," Journal of Financial Services Research, vol. 10, no. 4, p. 333, 1996.

[6] J. H. Gilkeson, J. A. List, and C. K. Ruff, "Evidence of Early Withdrawal in Time Deposit Portfolios," Journal of Financial Services Research, vol. 15, no. 2, pp. 103-122, 1999.

[7] R. Brooks, "Computing yields on enhanced CDs," Financial Services Review, vol. 5, no. 1, pp. 31-42, 1996.

[8] T. Tolstykh, J. Lee, S. Vafai, and J. B. Stock, "Carboxyl methylation regulates phosphoprotein phosphatase $2 \mathrm{~A}$ by controlling the association of regulatory B subunits," The EMBO Journal, vol. 19, no. 21, pp. 5682-5691, 2000.

[9] W. R. Turner, K. Brandon, T. M. Brooks, R. Costanza, G. A. B. da Fonseca, and R. Portela, "Global conservation of biodiversity and ecosystem services," BioScience, vol. 57, no. 10, pp. 868-873, 2007.

[10] B. N. Cline and R. Brooks, "Embedded options in enhanced certificates of deposit," Financial Services Review, vol. 13, no. 1, pp. 19-32, 2004.

[11] S. Xu, H. Lv, H. Liu, and A. Liu, "Robust control of disturbed fractional-order economical chaotic systems with uncertain parameters," Complexity, vol. 2019, Article ID 7567695, 13 pages, 2019.

[12] C.-F. Wang and W. Zhang, "Interest rate risk measurement and management of commercial banks with embedded options," Convexity Gap Model, Journal of Management Science, vol. 10, pp. 21-29, 2001, in Chinese.

[13] D. Luo and D. Wan, "Interest rate risk control of bank balance sheets with implicit options," System Engineering Theory and Practice, vol. 8, pp. 55-60, 2002.

[14] Z. Zheng and H. Lin, "Research on China's default risk premium," Securities Market Herald, vol. 6, pp. 41-44, 2003.

[15] X. Ren and S. Li, "Deposit product pricing linked to the range of income and exchange rate," Changes Journal of Tongji University, vol. 4, pp. 550-553, 2005.

[16] F. Yang, "Duration technology and commercial bank interest rate risk management based on implicit options," Technology and Management, vol. 6, pp. 104-112, 2006.
[17] J. Dai, "Identification and risk management of implied options in bank assets and liabilities," Business Research, vol. 4, pp. 65-68, 2006.

[18] C. Yi and D. Liu, "Research on interest rate risk management of implicit options in commercial banks finance and economics theory and practice," Financial Research, vol. 4, pp. 19-23, 2007.

[19] Z.-L. Zheng and H. Lin, "Decomposition and pricing of embedded options in assets and liabilities of bank," Financial Research, vol. 7, pp. 24-32, 2004, in Chinese.

[20] C. Liu, C. Xu, and Z. Xie, "Analysis of early loan repayment and its implied options," Journal of Applied Mathematics and Computational Mathematics, vol. 2, pp. 104-108, 2006.

[21] L. Zhu, M. Lou, and C. Ting, "Applied research on implied option pricing of bank of China debt," Times Finance, vol. 8, pp. 40-41, 2006.

[22] L. Zhu, M. Lou, and C. Ting, "Applied research on implied option pricing of bank liabilities in my country," Journal of Hebei University of Science and Technology (Social Science Edition), vol. 3, pp. 7-11, 2006.

[23] H.-P. Xia, M.-B. Zhou, and X.-M. Wang, "The influence of embedded options in deposit and loan on interest rate risk of commercial banks in China," Financial Research, vol. 9, pp. 138-150, 2007, in Chinese.

[24] E.-L. Tang, Y. Zhou, and W. Xiang, "Identification and pricing of prepayment options for floating rate mortgage," Journal of Anqing Normal University, vol. 1, pp. 26-29, 2018, in Chinese.

[25] E.-L. Tang, "Research on the penalty interest level of early withdrawal of time deposit in bank based on embedded option," Journal of Changchun University of Technology, vol. 6, pp. 104-108, 2020, in Chinese.

[26] B. N. Cline and R. Brooks, "Embedded options in enhanced certificates of deposit," Financial Services Review, vol. 13, pp. 19-32, 2004.

[27] L. Che, "Application of effective duration in CMO securities product design based on option adjusted spread," China's Foreign Capital, vol. 10, pp. 12-14, 2012.

[28] H.-P. Xia, M.-B. Zhou, and X.-M. Wang, "The influence of embedded options in deposit and loan on interest rate risk of commercial banks in China," Financial Research, vol. 9, pp. 138-150, 2007, in Chinese.

[29] C.-F. Wang and W. Zhang, "Interest rate risk measurement and management of commercial banks with embedded options: convexity gap model," Journal of Management Science, vol. 10, pp. 21-29, 2001, in Chinese.

[30] Y. Fan, M. Gu, and X.-H. Zheng, "Application of option adjusted spread model (OAS) in interest rate risk management of commercial banks," Technology and Management, vol. 2, pp. 72-75, 2003, in Chinese.

[31] E. Tang and W. Du, "Measuring interest rate risk with embedded option using HPL-MC method in fuzzy and stochastic environment," Journal of Mathematics, vol. 2020, Article ID 7410909, 13 pages, 2020.

[32] H. Lin and Z.-L. Zheng, "A review of term structure of interest rate," Journal of Management Science, vol. 10, pp. 79-93, 2007.

[33] M. Johannes, "The statistical and economic role of jumps in continuous-time interest rate models," Journal of Finance, vol. 59, pp. 227-260, 2004.

[34] J. Hull and A. White, "Bond option pricing based on a model for the valuation of bond prices," Advances in Futures and Options Research, vol. 6, pp. 1-13, 1993.

[35] S. R. Das, "The surprise element: jumps in interest rates," Journal of Econometrics, vol. 106, pp. 27-65, 2002. 
[36] F.-Q. Lin, J.-H. Ma, and X.-F. Ge, "Monte Carlo simulation and improvement of embedded option pricing of deposit and loan interest rate," Collected Essays on Finance and Economics, vol. 2, pp. 64-70, 2010.

[37] J. Benson Durham, "Jump-diffusion processes and affine term structure models: additional closed-form approximate solutions, distributional assumptions for jumps, and parameter estimates," in Proceedings of the Finance and Economics Discussion Series, pp. 33-53, Washington, DC, USA, 2005.

[38] G. Paul, Monte Carlo Methods in Financial Engineering, Higher Education Press, Beijing, China, 2008.

[39] S. Raymar and M. Zwecher, "Monte Carlo valuation of American call options on the maximum of several stocks," Journal of Derivatives, vol. 5, pp. 7-20, 1997.

[40] B. Papatheodorou, "Enhanced Monte Carlo methods for pricing and hedging exotic option," pp. 7-22, Oxford University, Oxford, UK, 2005, Doctoral Dissertation. 